\title{
Subjetividade e afeto em Zizek e Johnston: controvérsias em torno da relação psicanálise- neurociências
}

\section{| 1 Jairo de Almeida Gama |}

Resumo: O artigo parte da ideia de que a compreensão dos processos de constituição do sujeito tem sofrido profundas mudanças nas últimas décadas. Essas mudanças foram produzidas por descrições advindas de campos diversos, em especial da articulação das neurociências e da psicologia cognitiva, que buscam estabelecer os processos cerebrais como cruciais na formação da subjetividade. Diante disso, observamos que inúmeros autores do campo psicanalítico ampliaram seu escopo investigativo para estabelecer um diálogo intelectual produtivo entre a psicanálise e esses dois campos do saber. O objetivo deste artigo de revisão é discutir e contrapor as abordagens teóricas de Slavoj Zizek e Adrian Johnston, dois filósofos de orientação lacaniana que buscaram essa aproximação, mas chegaram a conclusões diversas no que tange ao significado e possibilidades teóricas dessa interlocução. Para Zizek, a abordagem neurocientífica falha em não reconhecer a dimensão radicalmente negativa do sujeito da psicanálise, sujeito este que rompe radicalmente com sua prévia base biológica. Johnston, ao contrário, fazendo uma cuidadosa leitura dos aspectos emocionais da subjetividade, busca articular de forma crítica, mas produtiva, esses diferentes campos de investigação. A conclusão é que a interlocução psicanálise-neurociências, embora problemática, é indispensável se pretendemos enriquecer as descrições teóricas sobre a gênese da subjetividade.

\author{
1 Universidade Federal de Juiz \\ de Fora e Faculdade de Ciências \\ Médicas e da Saúde de Juiz de \\ Fora. Juiz de Fora-MG, Brasil \\ (jairogama@gmail.com)
}


O neurocientista e psiquiatra Eric Kandel, premiado com o Nobel de Medicina e Fisiologia devido ao seu trabalho sobre as bases neurobiológicas da memória, causou alvoroço no meio científico ao defender, em dois comentados artigos, a articulação programática da biologia e da psicanálise (KANDEL, 1998; 1999). Para ele, a psiquiatria dependeria, para seu desenvolvimento futuro, de que o ensino, a pesquisa e a clínica psiquiátrica tivessem um embasamento neuro-psicanalítico. Defendendo as ideias originais de Freud, mas argumentando que a psicanálise estaria em declínio em função da falta de pesquisa com validade científica, o autor propõe que a psicanálise se torne um ramo da biologia. Embora suas ideias esbarrem em limites teóricos, em função de não considerar a renovação conceitual e clínica produzida por inúmeros autores pós-freudianos, entre eles Lacan e Winnicott, sua provocadora formulação teve o mérito de expor as dificuldades epistemológicas e clínicas em que se encontra a psiquiatria contemporânea. Nessa mesma linha, o psicanalista lacaniano François Ansermet (2014) afirmou ${ }^{1}$ que a articulação psicanálise-neurociências não é apenas necessária para resgatar a psiquiatria do atual limite biológico reducionista-eliminativista que ela se impôs, mas também para enriquecer as descrições teóricas desses dois campos de saber.

De fato, inúmeros psicanalistas (SOLMS; TURNBULL, 2002; ANSERMET; MAGISTRETTI, 2007; OUSS et al., 2009; POMMIER,2004), por razões que não dizem respeito estritamente à psiquiatria, se colocaram a tarefa de pensar tal articulação. Da mesma forma, autores do campo neurocientífico (DAMÁSIO, 2000; KANDELL, 1998; LeDOUX, 2002) ressaltam o valor das descobertas freudianas e da operacionalidade heurística de concepções seminais da psicanálise. Dada a rápida evolução das pesquisas empíricas neurocientíficas sobre a mente em seus diversos aspectos, e em função da grande produção teórica que psicanalistas estão realizando em estreita conexão com neurobiólogos, não é mais plausível aceitar as descrições caricaturais que parte do campo psicanalítico ainda realiza da neurobiologia.

A visão disseminada de que se dialogarmos com as neurociências estaremos nos afastando da subjetividade, da liberdade ou da singularidade de cada um de nós não pode mais ser defendida desde as novas descrições do cérebro como sede de operações complexas que, justamente, sustentam toda possibilidade de variedade e singularidades possíveis. Essa é uma mudança significativa. Acreditamos que a interlocução dessas áreas de pesquisas é crucial por duas 
razões. A primeira é que formular um diálogo produtivo entre a psicanálise e

as neurociências sobre a constituição do sujeito poderá ampliar o entendimento dos fenômenos subjetivos, mostrando os avanços e limites que ambos os campos possuem, abrindo a possibilidade de forjar conceitos que diminuam a lacuna epistêmica entre esses campos. A segunda razão é que criar descrições dos fenômenos mentais na interface mente-cérebro poderá gerar possibilidades novas de entendimento de fenômenos psicopatológicos, assim como formas de cuidado híbridas e com maior nível de complexidade, aposentando a velha dicotomia que opõe psicofarmacoterapia, psicoterapia e intervenções sociais em suas diferentes facetas. Embora na prática cotidiana dos atendimentos públicos e privados isso já aconteça, persistem na teoria disputas e desconfianças teóricas que se expressam de inúmeras maneiras, gerando consequências negativas para aqueles que sofrem de problemas mentais (GAMA, 2012).

Este artigo analisa as ideias, proposiçōes e dificuldades de dois autores que tentaram articular uma aproximação teórica dos dois campos. Slavoj Zizek (2008) e Adrian Johnston (2013) são filósofos de orientação hegeliano-lacaniana e realizaram uma importante contribuição ao debate em foco. Buscando traçar similaridades e diferenças entre as ideias de Freud e Lacan em comparação com neurocientistas contemporâneos, eles chegaram a conclusões opostas. Para Zizek (2008), importa formular a lacuna epistemológica de maneira correta para apontar o salto ontológico do sujeito sobre a biologia, enquanto para Johnston (2013), o estatuto teórico das emoções e seu papel na constituição subjetiva indicam uma possibilidade de articulação nova, promissora e inadiável.

\section{Zizek, as neurociências e o sujeito}

A princípio Zizek deseja formular e estabelecer a lacuna cérebro-mente nos termos adequados. Seu objetivo não é preencher a lacuna explicativa, mas formulá-la enquanto tal, realizando uma análise conceitual rigorosa dos principais trabalhos neurocientíficos contemporâneos sobre a constituição da mente ou da interface cérebro-mente. Zizek afirma que é como "verdadeiros freudianos" que devemos encarar a questão colocada pelas neurociências e o cognitivismo de uma maneira radical, não pressupondo um eu mais profundo e independente dos mecanismos neuronais, mas ao contrário, extrair da constatação das bases neurobiológicas da mente suas maiores consequências. 
Em A visão em paralaxe (2008), o autor se concentra na discussão sobre a maneira de proceder quanto ao "problema difícil" da filosofia da mente, a investigação da complexa passagem do organismo ao sujeito, ou como ele a nomeia, a "explosão ontológica”. Ele está de acordo com as perspectivas cognitivistas de que o self não tem um núcleo substancial, isto é, que não existe no sujeito uma substância real localizável. Ele compara o self a uma tela de computador, uma interface de mecanismos neurais com o mundo. Esse self virtual sem consistência, entretanto, possui uma organização; ele existe enquanto padrão relacional.

Essa questão, para o autor, abre um debate fundamental sobre a liberdade, isto é, se existe ou não um ato verdadeiramente livre. Sua pergunta fundamental, então, é "Como é possível um ato livre? Há causalidade na liberdade?” (ZIZEK, 2008 , p. 279). A pergunta faz sentido porque sendo o self virtual, ou seja, sendo ele supostamente um efeito de tais circuitos neuroquímicos, seria ele capaz de ter autonomia em relação aos mecanismos neurais subjacentes? $\mathrm{O}$ ato ético, problema central no pensamento zizekiano, está aqui colocado. A questão da liberdade em Zizek abre um campo de especulaçôes sobre a subjetividade humana, sua autonomia, constituição e regras de funcionamento que nos interessa diretamente. Para ele, a negação ou a frustração da tendência ao prazer, interrompendo o desenlace que seguiria um esquema prévio ou supostamente natural, é o modelo de ato ético, explicando em parte a aproximação teórica que o autor realiza entre ato ético e a pulsão de morte freudiana (além do princípio do prazer).

$\mathrm{O}$ ato ético é negativo em sua essência, rompendo com o círculo fechado de mecanismos determinísticos e promovendo o que ele denomina como "abertura ontológica" (ZIZEK, 2008, p. 274). Abertura ontológica, para Zizek, significa o rompimento do determinismo causal através da inserção de um campo de possibilidades numa estrutura temporal dada e a escolha de qual possibilidade irá me determinar. Liberdade e abertura ontológica apontam para o reconhecimento de qual necessidade anterior será endossada pelo self. Como ele diz: "Portanto, esse excesso do efeito sobre suas causas também significa que o efeito é, retroativamente, a causa de sua causa; esse circuito temporal é a estrutura mínima da vida” (ZIZEK, 2008, p. 276).

Visando a dar uma resposta à questão da liberdade, Zizek, em primeiro lugar, toma um caminho que vai contra duas concepções: o idealismo, que considera o cérebro apenas uma máquina de relés e, portanto, sem papel causal fundamental, 
e o materialismo vulgar, que mantém uma ideia mecanicista e determinista

da realidade. Essas duas concepçôes não consideram o cérebro como sede de mecanismos complexos e dialéticos (MALABOU, 2004) capaz de plasticidade e interação ambiental num tal nível que não podemos falar nem em determinação genética simples nem em estrutura rígida pré-programada. A programação genética cerebral configura um sistema aberto e que se automodela, sendo a mente um reflexo do projeto de interação com o ambiente (Cf. MALABOU, 2004; ZIZEK, 2008, JOHNSTON, 2010). A concepção da mente como estrutura aberta a mudanças e pré-programada, não à repetição, mas à invenção de padrões na relação com o ambiente, produzirá conseqüuncias de longo alcance.

O ponto central não é apenas romper a cadeia causal, mas escolher qual cadeia causal irá me determinar. A concepção hegeliana de "postular os pressupostos” é aqui fundamental para entender a ideia zizekiana de que a causalidade de um evento só é compreendida a posteriori, isto é, ele é visto em perspectiva. É como se, antes, a causa não existisse como possibilidade, depois do evento acontecido se constitui a certeza de que, desde sempre, ela já existia. Esse paradoxo faz Zizek propor um "mínimo idealismo" nesse processo. Para ele, esse núcleo mínimo que permite, das necessidades possíveis, se criar um espaço para a escolha da necessidade que me determinará, é propriamente o sujeito. A questão central nesse debate será, então, correlacionar o sujeito a uma estrutura especificamente neural. O ponto que o autor coloca, portanto, é como o self, sendo “apenas" uma interface com o mundo, sem nenhuma existência concreta, sem nenhum substrato orgânico, e dessa forma concordando com as teorias materialistasreducionistas, mesmo assim ativa um campo experiencial livre, determinando sua causalidade orgânica anterior. Para alcançar uma solução para o problema do limite neuronal gerador do salto ontológico, Zizek realiza uma leitura crítica sobre a natureza neural do self e da consciência com diversos neurocientistas, dentre eles Antonio Damásio e Thomas Metzinger.

Damásio, grosso modo, divide teoricamente o self em três níveis: proto-self, self nuclear e self autobiográfico. O proto-self é não consciente, neuro-orgânico, constituído por padrões neurais que mapeiam a relação do organismo com o ambiente no intuito de manter a homeostase. Toda vez que o proto-self é modificado pelo encontro com algum objeto, surge o self-nuclear, o embriāo da consciência de si, "o próprio pensamento de ser si - o próprio sentir-se - como ser 
individual envolvido no processo de conhecer a própria existência e a existência de outros" (ZIZEK, 2008, p. 300). Esse processo é um mapeamento neural, sendo também uma representação não verbal de um sentimento. Para ele, um sentimento representa a modificação do organismo no encontro com o objeto, formando um padrão neural novo.

O self, para Damásio, torna-se autoconsciente no ato de mapear a mudança neural produzida pelo encontro do organismo com o objeto. Em resumo, a interação do organismo com o objeto gera outro nível de representação no cérebro, um mapa de segunda ordem que registra as mudanças produzidas por essa interação que afeta o organismo, isto é, o mapa "organismo-interagindo-com-o-objeto" gera um mapa de segunda ordem, digamos, um mapa-self. Embora não linguístico, esse mapa-self representa emocionalmente o processo de afetação. Esse mapa é o que Damásio afirma que origina um "mínimo de reflexividade" (DAMÁSIO, apud ZIZEK, p. 302). Por fim, temos o selfautobiográfico que, baseado no self nuclear, acrescenta a este uma narrativa baseada em experiências passadas e projetos futuros. É um self que se organiza pela narrativa simbólica de si.

Para Zizek, o self nuclear damasiano representa a ruptura com qualquer homeostase, considerando essa estrutura correlata ao vazio intrínseco da subjetividade. O sujeito negativo e vazio se opõe ao proto-self ou eu-prazer neurobiológico regulador da homeostase orgânica, assim como ao self narrativo ou simbólico-narrativo. Enquanto o proto-selfe o self autobiográfico visam à homeostase psíquica, o self nuclear aponta para a interrupção da regularidade, o rompimento da homeostase gerada pelo encontro com o ambiente ao redor. Mais que isso, o próprio self nuclear também seria uma fonte de perturbação homeostática, pois o efeito de identificar a si mesmo enquanto estrutura vazia engendra uma oposição com o self autobiográfico, narrativo e construtor de sentido.

O self nuclear seria, nessa acepção, não assimilável e não simbolizável, pois marca uma singularidade traumática não relacionada a uma estrutura de sentido. Por outro lado, o self autobiográfico significa a formação de uma nova homeostase, como uma segunda natureza humana constituída pela narrativa simbólica de si. (ZIZEK, 2008, p. 283). Portanto, a configuração de um self totalizado e organizado escamoteia no seu âmago aspectos traumáticos e intrinsicamente "patológicos". Essa não integração dialética permite a ele dizer que o mental "explode" a partir de um limite neuronal e não apenas que o mental se baseia 
no neuronal ou depende do neuronal. Em suma, se existe uma estrutura que

se singulariza radicalmente nesse encadeamento de mapeamentos da relação do organismo com o ambiente, este é o sujeito/self nuclear. A autoconsciência daí advinda é traumática por desvelar a si mesma como oposta tanto ao organismo biológico quanto à narratividade de si.

Aprofundando esse diálogo, Zizek estabelece uma leitura de um filósofo que possui intensa interlocução e pesquisas com neurocientistas: Thomas Metzinger (2004). Metzinger afirma que o selfé o "conteúdo de um automodelo fenomenalmente transparente" (METZINGER apud ZIZEK, p. 288), ou seja, nosso cérebro é organizado para tornar transparente o processo gerador das experiências fenomenais vivenciadas. $\mathrm{O}$ processo gerador da percepção do mundo e de si mesmo permitem a experiência do mundo e do eu como dados da realidade, sem ter a necessidade de refazer o processo gerador da experiência.

Esse "fechamento autoepistêmico", isto é, essa incapacidade de conhecer o mundo e a nós mesmos é, para Metzinger, produto de uma vantagem evolucionária que possibilita a relativa e bem-sucedida acoplagem ao mundo, porque "permite ao sistema concentrar-se no resultado da atividade e não se perder na exploração introspectiva dos passos que levaram a ele" (METZINGER apud ZIZEK, p. 289). Novamente, a similaridade dessa definição com o eu lacaniano é clara. Para Lacan, o eu é uma imagem forjada e capturada como objeto externo, uma ilusão sedimentada na relação com o outro (LACAN, 1985) que permite não só termos um corpo como sermos um corpo com uma mente. $\mathrm{Na}$ perspectiva lacaniana, o eu é um objeto "com quem nos identificamos na transparência de nossa autoexperiência” (ZIZEK, 2008, p. 290). A confluência das teses de Metzinger e Lacan é, portanto, ressaltada por Zizek.

A ideia do eu como ficção representacional (“ilusão do usuário") é bem desenvolvida por Metzinger quando ele explica as três metáforas da mente humana. A primeira é a da caverna de Platão, que Metzinger redescreve afirmando que, diferentemente da versão original platônica, não há na caverna um self amarrado lá no interior e, portanto, ele não pode sair para o exterior e ver a luz do sol do conhecimento verdadeiro. Não há um homúnculo amarrado nas profundezas da caverna e cuja sombra é projetada em sua parede. A caverna está vazia, a sombra projetada é da caverna em si. Ela própria, enquanto caverna, com suas muitas paredes, projeta sua sombra gerando a ilusão de um ser em seu interior. 
A segunda metáfora é a representacionalista. Nela, a mente seria um "mapa multidimensional e dinâmico do mundo" (ZIZEK, p. 294)m que se parece com aqueles mapas externos que vemos em parques e metrôs, onde uma seta aponta sua localização. $\mathrm{O}$ mapa representa a realidade ao mesmo tempo em que representa o self. O selfé a seta no mapa. Mas a questão fundamental é que esse mapa de si é autotransparente, isto é, ele não se percebe como uma seta que organiza sua localização na realidade, mas age como habitando aquela realidade de fato. Aqui vemos, novamente, como Zizek aproxima essa descrição do self com a noção de sujeito lacaniano. O sujeito é um significante linguístico, uma marca assemântica que orienta o organismo (o self nuclear damasiano).

A terceira metáfora é a do simulador total de voo. Como num aeroplano que simula um voo, assim "planamos" na realidade. Mas, diferentemente de haver um piloto que sabe da simulação, no nosso caso, ou seja, no caso do nosso cérebro, não há um piloto. O piloto é um self que foi gerado dentro do próprio simulador, e essa informação ainda não foi passada ao processador do voo. $\mathrm{O}$ piloto não sabe que ele já está, desde sempre, num voo virtual.

Entretanto, Zizek faz uma crítica muito pertinente à metáfora da caverna. Ora, se podemos criar uma ficção de um observador, não podemos inventar a função de observar. Essa função não é uma ficção. Zizek afirma que Metzinger comete uma imprecisão ao não fazer essa distinção, embora ele se aproxime de Lacan ao dizer que existe "algo", um sistema gerador de um pensamento que não é o self autotransparente. $\mathrm{O}$ eu enquanto objeto ficcional é distinto de um $\mathrm{X}$ que pensa, embora seja um X não substancial. Esse X indefinido e indefinível é o sujeito da enunciação, isto é, um "algo" que vive no sujeito e que produz o movimento gerador do sujeito do enunciado. ${ }^{3}$

\section{Zizek e o problema da emoção}

O diálogo psicanalítico que Zizek estabelece com as neurociências e o cognitivismo vai ganhando diferentes articulaçóes e alcançando estratos explicativos cada vez mais complexos. Continuando o trabalho, ele afirma que esse "X que pensa" não substancial será novamente trabalhado por Damásio numa perspectiva bastante diferente. Este vai propor um pensamento que é marcado pela emoção. Ele afirma: "o vínculo constitutivo e necessário entre emoção e consciência: a consciência é uma reação emocional” (ZIZEK, p. 299). 
Reação emocional que ocorre em função do mapeamento de uma mudança

na homeostase do organismo, uma modificação interna causada pelo encontro com um objeto externo. Zizek, entretanto, faz uma crítica; ele entende que Damásio se equivoca porque despreza o fato de sermos animais de fala, sendo que ao não levar em conta a importância dos elementos linguísticos, passa a não reconhecer o significante que determina o sujeito. Para haver um self com um mínimo de reflexividade, deve haver um significante linguístico que o marca. Em outras palavras, Damásio afirma que no mapeamento de segunda ordem ocorre a autoconsciência, enquanto Zizek vê nesse processo apenas um novo mapeamento impossível de explicar a passagem de organismo para o sujeito. Para que isso ocorra, deve haver "algum tipo de autorreferência", ou seja, "um curto-circuito entre os dois níveis de representação” (ZIZEK, 2008, p. 304), um salto entre o processo cerebral e o fenômeno da consciência.

Esse processo, para Zizek, não pode ser compreendido sem levarmos em conta o papel do significante, ou seja, uma marca linguística que represente o sujeito. $\mathrm{O}$ self nuclear, para Zizek, se transubstancia quando do encontro com a linguagem, gerando o sujeito enquanto significante vazio e estável que permanece o mesmo na vida do organismo. Esse sujeito formal, linguístico e vazio, ponto de marcação pura e sem sentido, é completamente separado e autônomo em relação ao corpo. Para Zizek: "Não sou o meu corpo (tenho um corpo, nunca 'sou' meu corpo diretamente, apesar de todas as descrições fenomenológicas sutis à MerleauPonty que tentam me convencer do contrário)” (p. 305). Em seguida, afirma: "Em lugar nenhum a lacuna que faz a separação entre o inconsciente das ciências do cérebro e o Inconsciente freudiano é mais claramente perceptível do que a propósito do estatuto das emoções" (ZIZEK, 2008, p. 307).

O problema das emoções aprofunda o debate, isto é, aponta para abordagens diversas nas neurociências e na psicanálise. A lacuna corpo-mente ganha uma nova dimensão e mostra toda a tensão entre os dois pontos de vista. Sobre esse ponto, é importante notar a diferença entre emoção e sentimento que Damásio e Zizek defendem.

Para Damásio, as emoções são orgânicas e instintuais, sendo o sentimento o efeito de uma subjetivação da emoção estando ligada ao self nuclear, ou seja, uma emoção bruta gera uma modificação no self nuclear que transforma aquela emoção num sentimento diferencial em relação às emoções instintuais básicas, 
complexificando-as. Após essa primeira tradução, ocorreria a segunda, dada pelo sentimento sócio-linguisticamente regulado. Antes do sentimento consciente haveria, portanto, uma emoção básica e natural e sua tradução em emoção de segundo nível. Só então essa emoção pode se transformar em sentimento, embora possa também permanecer uma emoção não consciente.

Para Zizek, igualmente, os sentimentos são narrativas simbólicas, mas as emoçôes não teriam apenas uma base orgânica, porque existiriam emoções especificamente humanas ligadas ao sujeito: angústia e horror. Esses "afetos" especificamente humanos concernem ao confronto do sujeito com o vazio ou a pura negatividade de si. Segundo Zizek: “As emoções especificamente 'humanas' (como a angústia) só surgem quando o animal humano perde seu ancoramento emocional nos instintos biológicos, e essa perda é completada pelas emoções simbolicamente reguladas enquanto 'segunda natureza do homem" (ZIZEK, 2008, p. 307). Portanto, para Zizek, a marca humana diferencial em relação aos outros animais é esse salto sobre a biologia emocional e a instauração da ordem do significante linguístico, causador de um afeto especificamente humano, desnaturalizado e marcado pelo horror do encontro com o vazio do sujeito, o encontro com a cadeia significante não substancial. Esses "afetos" não seriam regulados pelos sentimentos sócio-simbolicamente organizados. Ele concebe a natureza emocional humana como fundamentalmente rompida com a natureza animal, com a linguagem fundando um sujeito autônomo em relação ao cérebro, cuja influência sobre a subjetividade seria extrínseca e não intrínsica à organização corporal em sua relação com o ambiente. Essa é, grosso modo, a forma que Zizek marca sua posição teórica sobre o debate psicanáliseneurociências, explicitando a lacuna mente-cérebro nos próprios termos neurocientíficos e recusando-se a estabelecer qualquer ponte teórica que ligue esses campos de pesquisa.

\section{O sujeito e a vida emocional em Johnston}

Zizek e Johnston partilham as mesmas bases filosóficas e psicanalíticas, assim como realizam uma leitura das teorias neurocientíficas com o mesmo interesse e criatividade. Diferem, no entanto, num ponto crucial: o lugar do sujeito na intrincada conexão cérebro-linguagem-emoção. É justamente na formulação da lacuna produzida pela inter-relação corpo-mente e o lugar central desempenhado 
pelas emoções que a divergência dos dois teóricos se torna aguda. Enquanto Zizek

é estritamente lacaniano, Johnston articula Lacan com as teses neurobiológicas da emoção. É importante ressalvar que Lacan não é unívoco na sua teorização da vida afetiva; no início dos seminários, ele ressalta a natureza intrincada do emocional e do linguístico, e só posteriormente vai assumindo uma posição teórica cada vez mais unidirecional, considerando o afeto apenas como um epifenômeno mobilizado pela cadeia significante. $\mathrm{O}$ que Johnston aponta é que Lacan, ao criticar o excessivo valor dado à expressão afetiva na teoria e prática psicanalítica de sua época, acaba por cair no polo oposto, excedendo na ênfase do aspecto linguístico-representacional. Johnston tentará revisar a ideia freudo-lacaniana de uma repartição radical entre afeto e representação (energia x estrutura ou significante $\mathrm{x}$ afeto), em concordância com neurocientistas que investigam as emoções (LeDOUX, 1996; PANKSEPP, 1998; DAMÁSIO, 1999).

Se para Lacan pensamos onde não se pensa, para Johnston, além disso, sentimos onde o eu não sente. Ele vai tentar mostrar que o recalque não opera apenas sobre as representações ideacionais ou linguísticas, mas que existem uma fratura e uma articulação imperfeita entre a estrutura afetiva biológica e simbolicamente constituída e a cadeia significante. Existem afetos inconscientes de origem biológica; entretanto, esses afetos não seriam acessíveis de maneira direta e inequívoca pelo indivíduo autoconsciente; seriam mediados e modulados, muitas vezes constituídos, por configurações "intelectuais, linguísticas e representacionais” (JOHNSTON, 2010, p. 77). Portanto, ele não defende um acesso subjetivo ao sentimento biológico bruto; ao contrário, propõe que a vida afetiva envolve mediações linguísticas que complicam o processo.

De fato, não existe acesso a sentimentos que já não sejam uma mistura de emoções orgânicas reconfiguradas pela cadeia linguística do sujeito. Esse fato é extremamente interessante, pois significa que tanto na teoria quanto na prática devemos trabalhar eventos afetivos articulados de diferentes maneiras. Por exemplo, devemos levar em consideração a estrutura ideo-afetiva (Affektbildung) em sua relação com o sentimento simbolicamente organizado (Empfindung), assim como os efeitos emocionais produzidos por esse desencontro intrínseco da tradução.

Essa proposição envolve mudanças tanto na versão psicanalítica dos afetos quanto na versão de boa parte da literatura neurocientífica. Nessa direção, Johnston defende uma divisão entre emoção (biológica, não consciente, 
pública), sentimento (mental, consciente, privada) e, detalhe fundamental, sentimento inconsciente.

Tomando o vocabulário damasiano como referência, ele afirma que esses três níveis de representação dos afetos são a consequência lógica da concepção de que a vida emocional é um efeito do constante automapeamento que o cérebro realiza na relação do organismo com os objetos do mundo. Esses mapeamentos são conscientes e não conscientes, isto é, existem padrões afetivos gerados na interação do sujeito com o ambiente que podem ou não se tornar conscientes. Como mostra Johnston, para Damásio existiriam sentimentos que são representaçôes inconscientes, e não energias motivacionais ou afetos instintivos puros. Esses sentimentos seriam as representações de emoções fisiologicamente organizadas e mapeadas no cérebro, ou seja, são as traduções das emoções.

Esses sentimentos total ou parcialmente inconscientes seriam de dois tipos: sentimentos não sentidos pela consciência em primeira pessoa e sentimentos sentidos de maneira imprecisa e confusa (misfelt), isto é, sentimentos traduzidos como ansiedade, culpa ou inquietação física (JOHNSTON, 2010, p. 80). Mas qual seria o estatuto desses sentimentos não conscientes? Para Johnston, seriam correlatos aos representantes pulsionais de Freud ou do gozo (jouis-sens) lacaniano, “justaposições híbridas e sínteses instáveis... nem estritamente corpóreo-libidinal nem subjetivo-significante” (JOHNSTON, 2013, p. 165-166). Como afirma Damásio: "Um sentimento de emoção é uma ideia do corpo quando é perturbado pelo processo emocional” (DAMÁSIO apud JOHNSTON, 2010, p. 81). É um processo que envolve etapas de mapeamento em diversos níveis, começando com as emoções fisiologicamente dadas, passando pela representação do corpo afetado pelos objetos (mapeamento de primeiro nível), daí para a associação com conteúdos e estilos cognitivos (mapeamento de segundo nível), para desse ponto alcançar o que chamamos de sentimentos conscientemente sentidos.

A perspectiva de Johnston é que o inconsciente pode ser pensado, pelo menos em parte, como "algo" que desliza de maneira errática entre esses diferentes níveis afetivos damasianos. O processo repressivo aqui é visto como defesa visando alcançar uma homeostase afetiva mínima que, entretanto, gera dissonâncias e perturbações nas traduções entre os níveis. É como se o animal humano tivesse uma distinção entre todas as espécies, pois seria naturalmente vulnerável a desarranjos entre os níveis representativos de sua interação com o ambiente. 
Para sustentar essa proposição, Johnston afirma que Freud, de fato, possui uma teoria emocional muito mais complexa e ambígua do que habitualmente se supõe. No que tange ao problema dos afetos inconscientes, Freud nunca teria alcançado uma solução plena. Em vários momentos de sua obra, ele oscila entre a negação e a afirmação da possibilidade desses afetos. Uma das tentativas freudianas de organizar conceitualmente o campo das emoções é sua proposição das noções de Affekt (afeto), Gefubl (emoção), Empfindung (sentimento) e Affektbildung (estrutura afetiva). Essas são noções criadas para tratar da complexidade do tema e referem-se a organizações específicas, isto é, possuem conexões e modulações emocionais e representacionais determinadas.

$\mathrm{O}$ termo Affektbildung, por exemplo, indica uma estrutura articulada ideo-afetiva inconsciente, uma unidade representacional complexa sujeita ao recalque. Essa estrutura teria uma inscrição psíquica, uma representação não linguística, que ao ser traduzido pelo significante com sentido público da língua materna no acesso à consciência já não seria exatamente o mesmo. Essa dificuldade de tradução, por sua vez, produz seus efeitos, gerando novos sentidos e novos sentimentos linguisticamente mediados. Em Lacan, os sentimentos mentem porque não traduzem a verdadeira fonte mobilizadora destes. Esta se encontra no Inconsciente estruturado como uma linguagem, ou seja, na cadeia significante.

O que Johnston quer ressaltar é que os sentimentos sentidos na consciência não esgotam toda a complexidade afetiva envolvida no processo. Afetos não sentidos (Affektbildung e Gehful) ficam de fora da clássica concepção lacaniana da vida emocional, impedindo a investigação de outras modalidades afetivo-sentimentais em jogo. Sentimentos narrados, afetos não sentidos e emoções geradas pelas dificuldades inerentes da tradução compõem uma rede extremamente complexa na vida subjetiva. ${ }^{4}$ Outro exemplo conexo de interpretação redutora feita por Lacan é a ideia freudiana contida no termo Reprasentanz, que significa, em Freud, um representante psíquico da pulsão que articularia representação e afeto. O recalque incide sobre o Reprasentanz, portanto sobre a estrutura ideo-afetiva em conjunto. Entretanto, Lacan inverte a explicação freudiana e considera que o termo designa outra função, a de representante de algo mais fundamental: Vorstellung, enquanto inscrição proto-significante no Real. Essa inversão transforma o significante no referente último do afeto. 
Desta maneira, ao falar de outra complexa noção freudiana, o Vorstellungreprasentanz, Lacan argumenta que tal termo corresponderia à cadeia significante (S1-S2), portanto, independente do afeto. Johnston contesta essa possibilidade, argumentando que essa interpretação difere da ideia freudiana. $\mathrm{O}$ representante da representação em Freud envolve inextrincavelmente representação e afeto (Reprasentaz), sujeito ao recalque. Existiria, portanto, uma base ideo-afetiva desde o início da vida psíquica. A asserção de que Freud nega a possibilidade de afetos serem recalcados é, portanto, falsa, e a famosa alegação de que para Freud não existiriam fenômenos emocionais inconscientes não se sustentaria.

Para Johnston, no que concerne aos afetos inconscientes, Freud muitas vezes hesita, mas Lacan propriamente escamoteia, isto é, esconde a dificuldade teórica no intuito de defender sua tese da prevalência do significante (JOHNSTON, 2013, p. 119). Para ele, a questão fundamental é que, com Freud e contra Lacan, significante e afeto estão intimamente conectados desde o início da vida psíquica, a separação afeto-ideia é uma “abstração secundária gerada pelo florescimento temporalmente alongado do psiquismo em si mesmo (florescimento este tornado possível em parte pela repressão) e a teorização psicanalítica dessa emergência” (idem, p. 126). Em suma, para Johnston, “afetos são significantes”. Sua concepção é a de que "a distinção afeto-significante é uma distinção interna à categoria de significante em si mesma” (idem, p. 209).

Significantes, para ele, não são apenas marcas gráficas e sonoras que se articulam diferencialmente numa rede temporal ou espacial. Sendo o significante uma categoria formal e não substancial, permite pensarmos que marcas afetivas também se estruturam nesse espaço lógico que representa a configuração neuronal-linguístico-fenomenológica do sujeito. Entretanto, Johnston, num certo momento teórico, parece se aproximar da concepção lacaniana da vida emocional, ao ressaltar que a palavra "afeto" pode ser caracterizada como um termo que enganosamente positiviza algo que é em si negativo. O termo “afeto" pode significar apenas uma radical assincronia entre emoções biológicas, sentimentos simbolicamente organizados e emoções surgidas do mapeamento de segunda ordem, assim como da própria assincronia.

Quanto ao sujeito, Johnston é claro quando afirma que ele não está de acordo nem com Zizek, nem com Damásio. Discorda de Damásio porque este não concede que no mapeamento de segunda ordem que gera o selfnuclear a linguagem 
criaria uma situação nova, que é a divisão ou descentramento do sujeito de sua base biológica no proto-self. Damásio acredita na materialidade biológica pura do self nuclear. E discorda de Zizek porque este defende a ideia de uma radical dessubstancialização do self nuclear quando da aquisição da linguagem.

Johnston assume uma posição intermediária. Para ele, a assunção do self nuclear produz uma divisão interna ao próprio, isto é, este se dividiria em dois: um permaneceria biologicamente constituído enquanto o outro seria transformado no clássico sujeito lacaniano. Johnston entende que o proto-self pode ser traduzido com bastante segurança como o $S$ não barrado lacaniano que em parte se configuraria no mapa ainda biológico do self nuclear. Enquanto o aspecto desse mesmo self transfigurado pela linguagem seria o $\$$ barrado lacaniano, ou seja, o sujeito do inconsciente.

De fato, com essa solução Johnston aproxima muito a interface cérebro-mente, tornando-a menos radicalmente dividida, porque no self nuclear conviveriam estruturas semiautônomas com alto grau de interações, combinaçôes, oposições, discrepâncias, mas ainda assim partícipes de um mesmo sistema. Como ele afirma, haveria um "full core self" e um "empty core self" dialeticamente relacionados. Resta-nos perguntar se esse self-nuclear dividido em dois não seria apenas uma solução de compromisso entre a teoria lacaniana e a proposição neurocientífica. Seria possível manter o mesmo estatuto do sujeito, sendo ele constituído pela cadeia significante, ao mesmo tempo que produzido pelo mapeamento neural de segunda ordem? O sistema neural e a cadeia significante são suficientes para explicar a constituição subjetiva?

A nosso ver, Johnston está fundamentalmente correto em suas proposições, mas talvez devêssemos levar em consideração outros aspectos, como os fenomenológicos, para trazer novos elementos na investigação da constituição subjetiva.

\section{Comentários finais}

As críticas de Johnston a Zizek atingem principalmente os seguintes pontos. O primeiro deles é a ideia zizekiana-lacaniana de que o inconsciente freudiano é incompatível com emoções não conscientes. Para Johnston, não há nada na teoria freudiana que inviabilize essa proposição. O segundo ponto é que Johnston não entende que as neurociências neguem a possibilidade de a rede sóciosimbólica mediar, influenciar e ordenar estruturas neuronais responsáveis pelas 
emoçōes básicas fisiológicas, assim como constituir sentimentos simbolicamente autônomos. Embora, nesse caso, Johnston defenda uma mudança na perspectiva da maioria dos neurocientistas. O terceiro ponto é que o autor defende que as neurociências estão produzindo um tipo não redutivo de materialismo dialético que está subvertendo as noçōes tradicionais de naturalismo e antinaturalismo, deixando para trás qualquer forma de cisão radical natureza-cultura.

Como vemos, Johnston se afasta de Zizek (e de Lacan) no que tange ao grau de desnaturalização da subjetividade. Para ele, a aquisição da linguagem não rompe radicalmente com o biológico, mas amortece, distorce e reconfigura profundamente as emoções biológicas e sua tradução. $\mathrm{O}$ inconsciente estaria na superfície, inscrito na barreira, no gap, na lacuna que existe no próprio self nuclear e na passagem/tradução emocional deste self para os sentimentos simbolicamente disponíveis no self narrativo. Nas brechas dos níveis emocionais é onde o sujeito circula.

Para Johnston, Zizek comete o erro de acreditar na ideia de que o sujeito é completamente desnaturalizado ao ser tomado pela rede significante, como se não restassem efeitos neuronais com consequências minimamente importantes sobre a subjetividade. Para Zizek, a castração simbólica romperia drasticamente com a natureza biológica do homem. Johnston, assumindo outra perspectiva, afirma que a desnaturalização nunca é completa, existiria sempre uma marca conflitual com resíduos que lembram a fratura, os antagonismos e discrepâncias entre o natural e o não natural, incorporados em diversos níveis e que estão implicados na cisão constitutiva do sujeito.

Em suma, enquanto Zizek aponta para uma explosão ontológica derivada de um limite neuronal que abre um campo subjetivo radicalmente autônomo, Johnston aponta para uma continuidade diferencial entre mente e corpo, que estaria na base dos problemas subjetivos humanos. Ele concorda com LeDoux (2002), que afirma que as emoçōes são expressōes cerebrais e corporais posteriormente categorizadas e diferenciadas de maneira sofisticada pela linguagem, criando nuances sentimentais impossíveis de serem realizadas por animais sem linguagem. Há uma coincidência do ponto de vista de LeDoux e Zizek com respeito à ideia de que o gap entre cérebro e mente gera uma emoção, isto é, a emoção ocorre em função da lacuna e não num lado ou outro da lacuna (JOHNSTON, 2013, p. 190). 
Além disso, há uma coincidência dos pontos de vista de LeDoux, Zizek e Johnston concernente ao efeito das fissuras que marcam as diversas etapas evolucionárias cerebrais e o profundo redesenho cortical produzido pela aquisição da linguagem. Os autores veem essa característica tanto como fraqueza quanto como força, isto é, como também responsável pela capacidade criativa da nossa espécie. Entretanto, Johnston não endossa a opinião zizekiana de que a linguagem quebra a influência de emoções biológicas sobre a subjetividade.

Apontando para a cisão humana, fonte de conflitos e desadaptação que provém dessa inadequação entre emoções primitivas, o sujeito-significante, e as exigências da rede simbólica, Johnston se aproxima das neurociências sem abrir mão das concepções psicanalíticas lacanianas. Para ele, os seres humanos são "criaturas de torções temporais", isto é, seres conectados a um passado evolucionário que deixa suas marcas biológicas que nunca são completamente superadas. $\mathrm{O}$ acesso ao simbólico supera apenas parcialmente nosso laço com a organização neuronal adquirida no longo processo de desenvolvimento da espécie.

Pensar que o ser humano é fundamentalmente desadaptado em função de sua imersão no mundo sócio-linguístico é imaginar duas coisas, ambas equivocadas: que a natureza é um todo harmônico e organizado, cujo rompimento levaria aos problemas especificamente humanos, e que o cérebro humano seria uma parte desse sistema quase perfeito. Na verdade, nem a natureza, nem o cérebro são vistos pelas ciências contemporâneas nesses termos, muito ao contrário. Não existe "A Natureza", assim como não existe "O Cérebro" enquanto perfeito "Sistema Funcional". ${ }^{5}$ Metáforas relacionando o cérebro a um eficiente computador ou a natureza a uma sabedoria oculta são imagens bastante distantes da ideia que se forma quando percebemos o cérebro como formado por estruturas acopladas e funcionalmente imperfeitas ou da natureza como um sistema naturalmente desarmônico.

Além disso, a ideia (equivocada) de que nossos problemas especificamente humanos nascem do rompimento radical com "a natureza" escamoteia a verdadeira consequência de sermos parcialmente presos a nossa história evolucionária. Se fôssemos totalmente desnaturalizados, como quer Zizek, talvez fôssemos mais adaptados ao mundo cultural do que nosso estado híbrido permite entrever. Ao contrário, para Johnston, esse hibridismo constitutivo é mais desadaptador e perturbador do que seria uma suposta imersão completa no mundo sócio-simbólico. 


\section{Referências}

ANSERMET, F.; MAGISTRETTI, P. Biology of freedom: neural plasticity, experience and the unconscious. New York Other Press, 2007.

DAMÁSIO, A. O mistério da consciência: do corpo e das emoçôes ao conhecimento de si. São Paulo: Companhia das Letras, 2000.

GAMA, J. R. A. A Reforma Psiquiátrica e seus críticos: considerações sobre a noção de doença mental e seus efeitos assistenciais. Physis: Revista de Saúde Coletiva. Rio de Janeiro, v. 22, n. 4, p. 1397-1417, 2012.

JOHNSTON, A. The misfeeling of what happens: Slavoj Zizek, Antonio Damasio and a materialist account of affects. Subjectivity, v. 3, p. 76-100, 2010.

. Affects are signifiers: the infinite judgment of a Lacanian Affective Neuroscience. Disponível em: <http://nessie-philo.com/Files/adrian_johnston___affects_are_signifiers. pdf> Acesso em: 10 abr. 2013.

. Self and emotional life: philosophy, psychoanalysis and neuroscience. New York: Columbia University Press, 2013.

KANDELL, E. R. A New Intellectual Framework for Psychiatry. Am. J. Psychiatry, v. 155, n. 4, p. 457-469, 1998.

- Biology and the future of psychoanalysis: a new intellectual framework for psychiatry revisited. Am J Psychiatry, v. 156, p. 505-524, 1999.

LACAN, L. O Seminário - Livro 2: O eu na teoria de Freud e na técnica da psicanálise. Texto estabelecido por Jacques-Alain Miller. Tradução de Marie Christine Laznik Penot. Rio de Janeiro: Jorge Zahar Editor, 1985.

LEDOUX, J. Synaptic self: how our brains become who we are. New York: Penguin Books, 2002.

MALABOU, C. Que faire de notre cerveau? Paris: Bayard, 2004.

METZINGER, T. Being no one: the self-model theory of subjectivity. Cambridge, MA: MIT Press, 2004.

. The ego tunnel: the science of mind and the myth of the self. New York: Basic Books, 2009.

. Reply to Zahavi: the value of historical scholarship. Psyche, v. 12, n. 2, May 2006.

OUSS, L. et al. Vers une neuropsychanalsye? Paris: Odile Jacob, 2009.

PANKSEPP, J. Affective neuroscience: the foundations of human and animal emotions. Oxford: Oxford University Press, 1998.

POMMIER, G. Comment les neurosciences démontrent la psychanalyse. Paris: Flamarion, 2004. 
SOLMS, M.; TURNBULL, O. The Brain and the Inner World: an introduction to the neuroscience of subjective experience. New York: Other Press, 2002.

ZAHAVI, D. Being Someone. Psyche, v. 11, n. 5, June 2005.

ZIZEK, S. A visão em paralaxe. São Paulo: Boitempo, 2008.

. The parallax view. Cambridge: MIT Press, 2006.

\section{Notas}

${ }^{1}$ Conferência proferida no Instituto de Psiquiatria da UFRJ em 2013.

${ }^{2}$ As noções de self, sujeito e eu não são correspondentes. Sujeito, na teoria lacaniana, diz respeito a um lugar vazio, no intervalo entre significantes linguísticos que se articulam diferencialmente, sendo portanto, uma estrutura evanescente, instável e assignificativa, que marca um lugar na relação com o Outro Simbólico. O eu é uma estrutura imaginária, objetificada em traços identificatórios que se articulam na formação da identidade e da organização narcísica. Já o selfé um termo que designa a estrutura completa da subjetividade. Esse termo não é usado na teoria lacaniana, embora Zizek a utilize aqui algumas vezes como similar ao eu e outras vezes simplesmente como o centro da subjetividade. Para evitar confusões terminológicas, usaremos self como um termo genérico que designa a organização subjetiva do organismo, seguindo em grande parte o pensamento do autor.

${ }^{3}$ Nesse ponto é interessante observar que a leitura fenomenológica de Zahavi (2005), em sua crítica a Metzinger, aponta numa outra direção. Para ele, esse "algo" gerador não é nenhum sujeito da enunciação, mas um self corporal-fenomenológico e pré-linguístico. Evidentemente, Zizek nesse ponto está ao lado dos cognitivistas. Para mais detalhes sobre a crítica a Metzinger, ver Zahavi (2005). Para a réplica, ver Metzinger(2006).

${ }^{4}$ Para uma leitura detalhada da relação entre sentimento e estrutura ideo-afetiva, ver a discussão de Johnston sobre a relação entre pudor e vergonha (JOHNSTON, 2013, p. 157-158).

${ }^{5} \mathrm{O}$ exemplo mais claro dessa ideia vem dos neurocientistas que estudam as emoções. Eles defendem a ideia de que o cérebro humano não é estruturado da maneira que comumente concebemos. Ao contrário de um sistema perfeito, esse órgão é uma bricolagem imperfeita, um aglomerado de sistemas que evoluíram de maneira não sincrônica e não muito organizada. Além disso, a aquisição da linguagem contribuiu para um redesenho cerebral que complicou ainda mais o processo de acoplagem com o meio (JOHNSTON, 2013). 
Subjectivity and affect in Zizek and Johnston: controversies in the relation psychoanalysisneurosciences

This article starts from the idea that understanding the subject constitution process has undergone profound changes in recent decades. These changes were produced by descriptions that come from various fields, in particular the articulation of neurosciences and cognitive psychology, seeking to establish the brain processes as crucial in the formation of subjectivity. Thus we observe that many authors of the psychoanalytic field expanded their investigative scope to establish a productive intellectual dialogue between psychoanalysis and these two fields of knowledge. The aim of this review article is to discuss and contrast the theoretical approaches of Slavoj Zizek and Adrian Johnston, two philosophers with Lacanian orientation that aimed this approach, but reached different conclusions with respect to the meaning and theoretical possibilities of this dialogue. For Zizek neuroscience approach fails in not recognizing the radically negative dimension of the subject of psychoanalysis, this subject that radically breaks with its previous biological basis. Johnston, on the contrary, doing a careful reading of the emotional aspects of subjectivity, seeks to articulate critically, but productive, these different fields of research. The conclusion is that psychoanalysis-neuroscience dialogue, although problematic, is indispensable if we are to enrich the theoretical descriptions of the genesis of subjectivity.

> Key words: psychoanalysis; neurosciences; subject; emotion; affect. 